Marquette University

e-Publications@Marquette

School of Dentistry Faculty Research and

Publications

Dentistry, School of

4-2012

\title{
Analysis of Abstracts Presented at the Prosthodontic Research Section of IADR General Sessions 2004-2005: Demographics, Publication Rates, and Factors Contributing to Publication
}

\author{
Damian J. Lee \\ University of Illinois at Chicago \\ Judy Chia-Chun Yuan \\ University of Illinois at Chicago \\ Soni Prasad \\ Marquette University, soni.prasad@marquette.edu \\ Valentim A. R. Barao \\ Aracatuba Dental School \\ Nodesh Shyamsunder \\ Nova Southeastern University
}

See next page for additional authors

Follow this and additional works at: https://epublications.marquette.edu/dentistry_fac

Part of the Dentistry Commons

\section{Recommended Citation}

Lee, Damian J.; Yuan, Judy Chia-Chun; Prasad, Soni; Barao, Valentim A. R.; Shyamsunder, Nodesh; and Sukotjo, Cortino, "Analysis of Abstracts Presented at the Prosthodontic Research Section of IADR General Sessions 2004-2005: Demographics, Publication Rates, and Factors Contributing to Publication" (2012). School of Dentistry Faculty Research and Publications. 231.

https://epublications.marquette.edu/dentistry_fac/231 


\section{Authors}

Damian J. Lee, Judy Chia-Chun Yuan, Soni Prasad, Valentim A. R. Barao, Nodesh Shyamsunder, and Cortino Sukotjo

This article is available at e-Publications@Marquette: https://epublications.marquette.edu/dentistry_fac/231 
Marquette University

e-Publications@Marquette

\section{Dentistry Faculty Research and Publications/School of Dentistry}

This paper is NOT THE PUBLISHED VERSION; but the author's final, peer-reviewed manuscript. The published version may be accessed by following the link in the citation below.

Journal of Prosthodontics, Vol. 21, No. 3 (April, 2012): 225-231. DOI. This article is (C) Wiley and permission has been granted for this version to appear in e-Publications@Marquette. Wiley does not grant permission for this article to be further copied/distributed or hosted elsewhere without the express permission from Wiley.

\section{Analysis of Abstracts Presented at the Prosthodontic Research Section of IADR General Sessions 2004-2005: Demographics, Publication Rates, and Factors Contributing to Publication}

\section{Damian J. Lee}

Department of Restorative Dentistry, University of Illinois at Chicago, College of Dentistry, Chicago, IL

Judy Chia-Chun Yuan

Department of Restorative Dentistry, University of Illinois at Chicago, College of Dentistry, Chicago, IL

Soni Prasad

Department of General Dental Science, Marquette University School of Dentistry, Milwaukee, WI

Valentim Adelino Ricardo Barão

Department of Restorative Dentistry, University of Illinois at Chicago College of Dentistry, Chicago, IL 
Department of Dental Materials and Prosthodontics, Aracatuba Dental School, Universidade Estadual Paulista (UNESP), Aracatuba, Brazil

\section{Nodesh Shyamsunder}

Department of Restorative Dentistry, University of Illinois at Chicago College of Dentistry, Chicago, IL

Nova Southeastern University, College of Dentistry, Fort Lauderdale-Davie, FL

\section{Cortino Sukotjo}

Department of Restorative Dentistry, University of Illinois at Chicago, College of Dentistry, Chicago, IL

Keywords

Research, manuscripts, publication rate, poster, presentations, IADR, prosthodontics

\section{Abstract}

Purpose: The purposes of this study were to describe the demographics of abstracts presented at the prosthodontics section of IADR General Sessions from 2004 to 2005, evaluate the publication rate of abstracts, and analyze the relationship between variables in abstracts and publication.

Materials and Methods: Prosthodontics research section abstracts from the IADR General Session in 2004 and 2005 were evaluated for: number of authors, presentation type, origin, affiliation, topic, study design, statistics, study outcome, and funding. The publication rate was calculated following a PubMed search. The journal of publication, year of publication, and the length of time before publication were analyzed. Descriptive statistics were used for the data analysis; the relationships between presentation type, study design, study outcome, statistics, funding, and publication were analyzed using logistic regression $(\alpha=0.05)$.

Results: From 346 abstracts, $37.0 \%$ were published. For oral presentations, $40.7 \%$ were published; $35.8 \%$ of poster presentations were published. The mean duration before publication was 26.4 months. North America had the most abstracts, and Europe had the most publications. Fixed prosthodontic research had the highest number and proportion for publication. A significant association with publication was noted for neutral study outcomes $(p=$ $0.018)$, studies with funding $(p=0.035)$, and abstracts from Europe $(p=0.001)$.

Conclusions: The majority of abstracts from the prosthodontics research section of IADR General Sessions from 2004 and 2005 remain unpublished. A significant association for publication was noted with neutral outcomes, funding, and abstracts from Europe.

Dissemination of knowledge can be considered the ultimate goal for all research. To accomplish this goal, many researchers present scientific findings at various meetings to their colleagues and peers. By publishing the research in peer-reviewed journals, researchers can 
distribute the newly acquired knowledge to the community for incorporation into practice or therapy. $\underline{1}$ Past studies have examined the rate of publications of abstracts presented at scientific meetings. $-\underline{122}$ The rate of publication varied widely, ranging from 22.1 to $62.3 \%$ in different medical and dental specialties. $1,4-\underline{4}-17,12, \underline{20}$ Studies have reported a range of 8 months to 31 months as the average time from the meeting to publication. studies have explored further, where factors such as type of presentation, statistical analysis, study design, study outcome, and funding and their influences on the likelihood of publication were examined. presentations, $, \underline{1}, \underline{9}, \underline{12}, \underline{13}, \underline{17}, \underline{18}, \underline{20}$ studies that reported positive outcomes, $\underline{2}, \underline{10}, \underline{23}, \underline{24}$ statistical significance, $, \underline{2}, \underline{10}, \underline{23}, \underline{24}$ and funding $\underline{25}$ were more likely to be published. The eventual publishing of new scientific knowledge may be a byproduct of any of these factors. The rate of publication from abstract presentations in prosthodontic meetings has not been widely investigated.

The International Association for Dental Research (IADR) is the leading organization in the dental research community. Historically, the number of abstracts presented at IADR General Sessions has been increasing, along with the number of participating institutions and countries. ${ }^{26}$ The prosthodontics section of the IADR is one of the oldest sections in the organization, with research areas ranging from in vitro laboratory research, animal research, theoretical engineering, clinical research, to epidemiology. $\underline{\text { 27 }}$ Despite an abundance of research activity, the outcome from the prosthodontics section, as represented by published manuscripts, is unknown. The purposes of this study were to (1) describe the demographics of the abstracts presented at the prosthodontics section of IADR General Sessions from 2004 to 2005 , (2) evaluate the rate of publication from the abstracts, and (3) analyze the relationship between variables found in abstracts and publication.

\section{Materials and methods}

The program notes for the Prosthodontics research section from the IADR $82^{\text {nd }}$ General Session (March 10-13, 2004; Honolulu, HI) and IADR 83 ${ }^{\text {rd }}$ General Session (March 9-12, 2005; Baltimore, MD) were obtained. The years 2004 and 2005 were selected for this study because having a span of 5 years allowed sufficient time to achieve publication and allowed for contemporary relevance in 2010. $\underline{12}$ Within the program notes, all abstracts from presentations were divided among six investigators. To ensure consistency and reliability among the investigators, calibration meetings were held on a regular basis to assess if all determinations coincided. Whenever there was a conflict or uncertainty, final group decisions were made.

The following variables were evaluated: number of authors, type of presentation, geographical origin, name of affiliation, abstract topic, study design, type of statistics, study outcome, and funding. For the number of authors, the total number of authors per abstract was tabulated and recorded. The type of presentation was classified as oral presentation or poster presentation. The study design of the abstract was divided into two categories: laboratory or clinical. The statistical analysis used in the abstract was defined as descriptive, analytical, or none. Study outcomes were classified as positive, negative, or neutral, based on a study by Hasenboehler et al. $\underline{24}$ Positive abstracts were defined as abstracts with significant differences between the study groups with positive conclusions or positive recommendations, favorable clinical outcomes, positive data derived from basic science studies, and identification of relevant 
independent variables, risk factors, etc. that contribute to a favorable outcome. Negative abstracts were defined as abstracts with significant differences between the study groups with negative conclusions and/or negative recommendation, adverse clinical outcomes, negative data derived from basic science studies, and identification of relevant independent variables, risk factors, etc. that contribute to an adverse outcome. Neutral abstracts were defined as abstracts with no significant differences between the study groups, or any clear conclusions or recommendations. The source of funding (industry, foundation, government, university, or none) was categorized based on a study by Birkhahn et al. $\underline{25}$ With respect to geographical origin, the countries reported in the abstracts were recorded and categorized by continent, modified from a study by Rahman and Fukui $\underline{28}$ as the following: North America, Europe, Asia, South America, and Others (Central America, Africa, and Oceania). Oceania was defined as Australia and proximate Pacific Islands. The ten most-represented countries were identified. The names of all affiliations and institutions in the abstract were recorded, and the ten most common institutions were identified. The abstracts of the prosthodontic research section were divided by topic of the presentation listed in the program notes and grouped.

After the variables within the abstracts were identified, the publication rate was evaluated by determining whether the abstract was published in a peer-reviewed journal. An electronic database search was performed, using PubMed (http://www.ncbi.nlm.nih.gov/ or http://www.pubmed.gov), based on a cross-reference search of the first and last names of the authors and keywords in the abstract. A Boolean operator (OR) that included all manuscripts by the first, second, and last authors were performed. $\underline{17}$ When multiple publications were identified, the Boolean operator (AND) was used to combine author names and keywords from the abstract title to obtain the corresponding manuscript. 18 Once the published abstract was identified and recorded, the published articles were further compared to the original abstract presented in the IADR program note. Articles with a publication date prior to the IADR meeting, published articles without access, and articles published in a language other than English were excluded from further analysis. Within the published manuscripts, the following data were collected, based on methods by Bagheri et al $\underline{6}$ and Kleweno et al: 11 journal of publication, year of publication, and duration of time between presentation and publication. To determine the length of time between abstract presentation and publication of full-length paper, the duration between the IADR general sessions (March 2004 or 2005) to publication was calculated in months.

Data were collected and entered into a software database (Microsoft Excel 2007; Microsoft, Seattle, WA). Statistical software (SPSS v17.0; SPSS Inc, Chicago, IL) was used for descriptive and statistical analyses. Frequency and percentages were calculated for variables (type of presentation, geographic origin, study design, type of statistics, study outcome, source of funding, topics, top ten countries, and top ten affiliations) found in abstracts and publications. The duration between presentation and publication was grouped into number of years. Logistic regression analysis was performed to assess the predicting factors related to publication, based on the variables found within the abstracts: type of presentation, study design, study outcome, type of statistics, and type of funding. To better examine the possibility of publication from a continent, logistic regressions were used to determine whether the "likelihood" of publication was significantly greater in each continent versus abstracts from all 
other continents. The publications were grouped based on the journals published, and the distribution was calculated. Statistical significance was defined as $p<0.05$.

\section{Results}

Three hundred seventy-one (371) abstracts were presented for the 2004 and 2005 IADR general sessions, 23 abstracts were withdrawn, and two keynote speaker abstracts were excluded, resulting in 346 total abstracts. Table 1 represents the demographic information on the abstracts and publications examined. The number of authors ranged from 1 to 9 , with a mean of 4.2. The majority of the presentations were poster, laboratory study by design, used analytical statistics, had a positive study outcome, and did not report any funding. North America had the highest number of abstracts, whereas Europe had the highest number of publications. Fixed prosthodontic research had the highest number and proportion for publication, followed by implant prosthodontic research.

Table 1. Abstract and publication demographics

Abstract variables

Type of presentation

Oral

Poster

Geographical origin

North America

Asia

Europe

South America

Others (Central America, Africa, and

Oceania)

Study design

Laboratory

Clinical

Type of statistics

Analytical

Descriptive

None

Study outcome

Positive

Negative

Neutral
Number of abstracts Number of publication and proportion $\mathrm{N}(\%)$ and proportion $\mathrm{N}(\%)$
$86(24.9)$

$260(75.1)$

$140(35.3)$

$110(27.7)$

$108(27.2)$

$32(8.1)$

7 (1.8)

$245(70.8)$

$101(29.2)$

94 (73.4)

$34(26.6)$

284 (82.1)

$34(9.8)$

28 (8.1)

218 (63.0)

29 (8.4)

99 (28.6)
35 (27.3)

93 (72.6)

45 (29.8)

38 (25.2)

55 (36.4)

10 (6.6)

3 (2.0)
107 (83.6)

14 (10.9)

7 (5.5)

71 (55.4)

11 (8.5)

46 (35.9) 


\begin{tabular}{|c|c|c|}
\hline Abstract variables & $\begin{array}{l}\text { Number of abstracts } \\
\text { and proportion } \mathrm{N}(\%)\end{array}$ & $\begin{array}{l}\text { Number } \\
\text { and prop }\end{array}$ \\
\hline \multicolumn{3}{|l|}{ Source of funding } \\
\hline None & $270(78.0)$ & $92(71.9)$ \\
\hline Industry & 35 (10.1) & $17(13.3)$ \\
\hline Government & $26(7.5)$ & $14(10.9)$ \\
\hline Foundation & $11(3.2)$ & $4(3.1)$ \\
\hline University & $4(1.2)$ & $1(0.8)$ \\
\hline \multicolumn{3}{|l|}{ Topics } \\
\hline Fixed prosthodontic research & $52(15.0)$ & $19(16.7)$ \\
\hline Assessment in color and esthetics & $39(11.2)$ & $15(13.2)$ \\
\hline $\begin{array}{l}\text { Complete denture and overdenture } \\
\text { research }\end{array}$ & $38(11.0)$ & $9(7.9)$ \\
\hline Implant prosthodontic research & $37(10.7)$ & $16(14.0)$ \\
\hline $\begin{array}{l}\text { Removable/maxillofacial prosthodontics } \\
\text { and articulators }\end{array}$ & $34(9.8)$ & $9(7.9)$ \\
\hline $\begin{array}{l}\text { Ceramics/metal ceramic systems in fixed } \\
\text { prosthodontics }\end{array}$ & $33(9.5)$ & $11(9.6)$ \\
\hline $\begin{array}{l}\text { Masticatory performance and oral } \\
\text { function }\end{array}$ & $33(9.5)$ & $11(9.6)$ \\
\hline $\begin{array}{l}\text { CAD/CAM, dental composites, fiber } \\
\text { composites, and mouth guard material }\end{array}$ & $24(6.9)$ & $5(4.4)$ \\
\hline $\begin{array}{l}\text { Clinical outcomes of prosthodontic } \\
\text { treatment }\end{array}$ & $24(6.9)$ & $9(7.9)$ \\
\hline $\begin{array}{l}\text { Restoration of endodontically treated } \\
\text { teeth }\end{array}$ & $19(5.5)$ & $7(6.1)$ \\
\hline $\begin{array}{l}\text { Biological and anatomical evaluations in } \\
\text { prosthodontics }\end{array}$ & $12(3.5)$ & $2(1.8)$ \\
\hline Lasers & $1(0.3)$ & $1(0.9)$ \\
\hline
\end{tabular}

Overall, $37.0 \%$ of the abstracts (128) were published in peer-reviewed journals. Out of 86 oral presentations, $40.7 \%$ of the abstracts (35) were published; out of 260 poster presentations, $35.8 \%$ of the abstracts (93) were published (Table 1). The mean duration of time to publication was 26.4 months, ranging from 0 to 67 months. Figure 1 represents the time elapsed since the IADR General Session. More than two-thirds of the abstracts were published within 3 years of the meeting. 


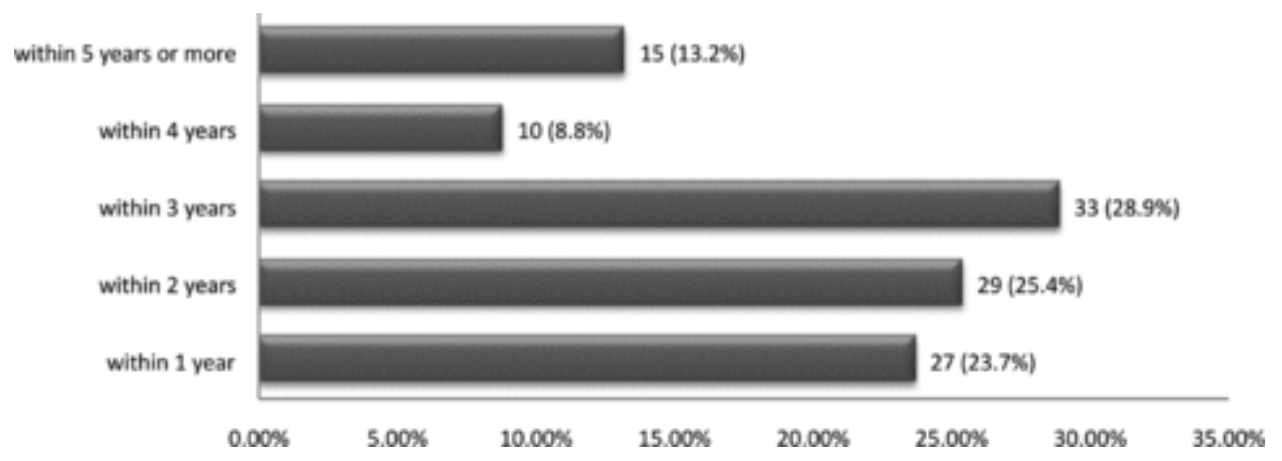

Figure 1 Rate of publications based on time elapsed from IADR general session.

Within the published articles, 14 were excluded because they were either published prior to the IADR Annual Session, were inaccessible, or were not published in English. The remaining 114 publications were further analyzed.

Among the countries, the US had the highest number of abstracts presented, as well as the highest number of publications (Table 2). The top four countries remained the same for abstracts and publication. Among the universities represented, the largest number of abstracts was from Tsurumi University from Japan; The Ohio State University in the US had the highest number of publications. Among the journals in which the abstracts were published, The Journal of Prosthetic Dentistry had the largest proportion of publications, followed by the Journal of Prosthodontics and Dental Materials (Fig 2).

Table 2. Top 10 proportion of abstracts and publications based on country and affiliation

$\begin{array}{cccc}\text { Top } 10 \text { countries } & \text { Number of abstracts } & \text { Top } 10 \text { countries for } & \text { Number of publication } \\ \text { for abstracts } & \text { and proportion N (\%) } & \text { publications } & \text { and proportion N (\%) }\end{array}$

$\begin{array}{llll}\text { United States } & 135(34.0) & \text { United States } & 44(33.3) \\ \text { Japan } & 79(19.9) & \text { Japan } & 21(15.9) \\ \text { Germany } & 51(12.8) & \text { Germany } & 17(12.9) \\ \text { Brazil } & 27(6.8) & \text { Brazil } & 9(6.8) \\ \text { United Kingdom } & 10(2.5) & \text { Netherlands } & 7(5.3) \\ \text { Turkey } & 9(2.3) & \text { Finland } & 5(3.8) \\ \text { Finland } & 8(2.0) & \text { Singapore } & 4(3.0) \\ \text { Netherlands } & 8(2.0) & \text { United Kingdom } & 4(3.0) \\ \text { China } & 7(1.8) & \text { Switzerland } & 3(2.3) \\ \text { South Korea } & 6(1.5) & \text { Turkey } & 3(2.3) \\ \text { Others (5 or fewer } & 57(14.4) & \text { Others (2 or fewer } & 15(11.4) \\ \text { abstracts) } & & \text { publications) } & \\ \text { Top 10 affiliations } & \text { Number of abstracts } & \text { Top 10 affiliations for } & \text { Number of publication } \\ \text { for abstracts } & \text { and proportion N (\%) } & \text { publications } & \text { and proportion N (\%) }\end{array}$




\begin{tabular}{|c|c|c|c|}
\hline $\begin{array}{l}\text { Top } 10 \text { countries } \\
\text { for abstracts }\end{array}$ & $\begin{array}{l}\text { Number of abstracts } \\
\text { and proportion } \mathrm{N}(\%)\end{array}$ & $\begin{array}{c}\text { Top } 10 \text { countries for } \\
\text { publications }\end{array}$ & $\begin{array}{l}\text { Number of publication } \\
\text { and proportion } \mathrm{N}(\%)\end{array}$ \\
\hline Tsurumi University & $17(3.7)$ & $\begin{array}{l}\text { The Ohio State } \\
\text { University }\end{array}$ & $9(6.1)$ \\
\hline $\begin{array}{l}\text { Tokyo Medical \& } \\
\text { Dental University }\end{array}$ & $15(3.3)$ & $\begin{array}{l}\text { Tokyo Medical and } \\
\text { Dental University }\end{array}$ & $7(4.7)$ \\
\hline $\begin{array}{l}\text { The Ohio State } \\
\text { University }\end{array}$ & $14(3.1)$ & $\begin{array}{l}\text { Christian-Albrechts } \\
\text { University }\end{array}$ & $7(4.7)$ \\
\hline $\begin{array}{l}\text { Christian-Albrechts } \\
\text { University }\end{array}$ & $10(2.2)$ & Univ. of Washington & $6(4.1)$ \\
\hline UCLA & $10(2.2)$ & Univ. of Turku & $4(2.7)$ \\
\hline $\begin{array}{l}\text { Uni Est. Paulista } \\
\text { Julio Mesquita }\end{array}$ & $10(2.2)$ & Univ. of Sao Paulo & $4(2.7)$ \\
\hline Baylor University & $9(2.0)$ & Nagasaki University & $4(2.7)$ \\
\hline Nihon University & $9(2.0)$ & UCLA & $3(2.0)$ \\
\hline Harvard University & $8(1.7)$ & Tsurumi University & $3(2.0)$ \\
\hline $\begin{array}{l}\text { Justus-Liebig } \\
\text { University }\end{array}$ & $8(1.7)$ & $\begin{array}{l}\text { National Univ. of } \\
\text { Singapore }\end{array}$ & $3(2.0)$ \\
\hline $\begin{array}{l}\text { Others (fewer than } 8 \\
\text { abstracts) }\end{array}$ & $349(76.0)$ & $\begin{array}{l}\text { Others ( } 2 \text { or fewer } \\
\text { publications) }\end{array}$ & $98(66.2)$ \\
\hline 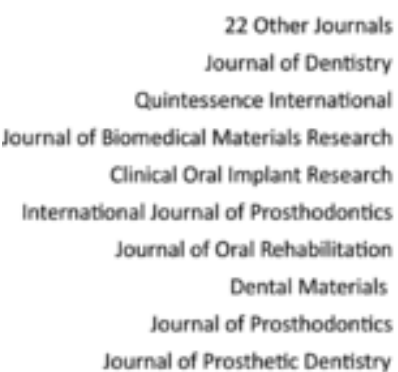 & 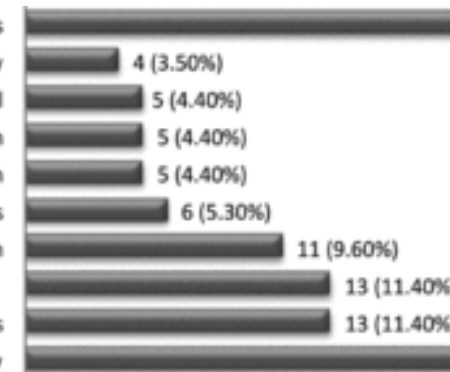 & & \\
\hline & $\begin{array}{llll}0.00 \% & 5.00 \% & 10.00 \% & 15.00\end{array}$ & $25.00 \%$ & \\
\hline
\end{tabular}

Figure 2 Distribution of publications by journal of publication.

A regression model for predicting factors related to publication is shown in Table 3 . A significant association with publication was noted for neutral study outcomes studies that reported funding, and abstracts from Europe. Although not significant, studies with statistics were 1.8 times more likely to get published.

Table 3. Analysis of factors related to abstracts leading to publication

Factor

Level

\section{Unpublished $\mathbf{N}$}

(\%)
Published N

(\%) p Odds ratio (95\% value $\quad \mathrm{Cl}$ )

$0.4121 .2(0.7,2.0)$

Presentation Oral

$51(59.3)$

35 (40.7)

type 


\begin{tabular}{|c|c|c|c|c|c|}
\hline \multirow[t]{2}{*}{ Factor } & Level & $\begin{array}{c}\text { Unpublished } \mathrm{N} \\
\text { (\%) }\end{array}$ & $\begin{array}{c}\text { Published N } \\
\text { (\%) }\end{array}$ & $\begin{array}{c}p \\
\text { value }\end{array}$ & $\begin{array}{l}\text { Odds ratio }(95 \% \\
\mathrm{Cl})\end{array}$ \\
\hline & Poster & $167(64.2)$ & $93(35.8)$ & & \\
\hline \multirow[t]{2}{*}{ Study design } & Laboratory & $151(61.6)$ & $94(38.4)$ & 0.41 & $1.2(0.8,2.0)$ \\
\hline & Clinical & $67(66.3)$ & 34 (33.7) & & \\
\hline \multirow[t]{2}{*}{ Funding } & Yes & $40(52.6)$ & $36(47.4)$ & $0.035^{\star \star}$ & $1.7(1.0,2.9)$ \\
\hline & No & $178(65.9)$ & $92(34.1)$ & & \\
\hline \multirow[t]{5}{*}{ Continent } & $\begin{array}{l}\mathrm{N} . \\
\text { America }\end{array}$ & 95 (67.9) & 45 (32.1) & 0.075 & $0.7(0.4,1.0)$ \\
\hline & Europe & 52 (48.6) & 55 (51.4) & $0.001^{\star *}$ & $2.2(1.4,3.4)$ \\
\hline & Asia & 74 (66.1) & 38 (33.9) & 0.291 & $0.8(0.5,1.2)$ \\
\hline & S. America & $22(68.8)$ & $10(31.3)$ & 0.411 & $0.7(0.3,1.6)$ \\
\hline & Others* & $3(50.0)$ & $3(50.0)$ & 0.547 & $1.6(0.3,8.2)$ \\
\hline \multirow[t]{2}{*}{ Statistics } & Yes & $197(61.9)$ & 121 (38.1) & 0.176 & $1.8(0.8,4.5)$ \\
\hline & No & $21(75)$ & $7(25)$ & & \\
\hline \multirow[t]{3}{*}{ Study outcome } & Positive & $147(67.4)$ & 71 (32.6) & & \\
\hline & Negative & 18 (62.1) & $11(37.9)$ & 0.565 & $1.3(0 / 6,2.8)$ \\
\hline & Neutral & $53(53.5)$ & $46(46.5)$ & $0.018^{\star \star}$ & $1.8(1.1,2.9)$ \\
\hline
\end{tabular}

- ${ }^{*}$ Central America, Africa, and Oceania.

- ${ }^{* *} p<0.05$ denotes significant difference.

\section{Discussion}

Valuable research data and knowledge cannot be disseminated unless they are published. The rate of publication was $37.0 \%$ for IADR abstracts. This is similar to other studies found in the medical and dental literature, where the rate of publication was often low, ranging from $27 \%$ to $46 \% . \underline{6}, \underline{17}, \underline{18}$ A study by Sprague et al showed that the reasons for the lack of publication were insufficient time, study in progress, other authors' responsibility for manuscript writing, lack of participation from co-authors, or low priority in publishing manuscripts. $\underline{19}$ Another study found that the level of interest or limitations in methodology discouraged the research from becoming a publication. $\underline{\underline{21}}$ This study did not address the reasons for the abstracts not being published. This aspect could be further explored in a future study.

A significant delay in publication may cause the scientific findings to be considered "outdated" and have "less significant scientific value."17 The mean time to publication was 26.4 months, and the majority of the publications occurred within 3 years of the meeting. In other dental specialties, a range of 18 months to 23.4 months was reported as the mean time to publication. $. \underline{6}, \underline{17}, \underline{18}$ The delay in publishing manuscripts after initial abstract presentation may have several reasons, including having only interim results, modification of manuscripts or content, a lengthy peer-review process, and waiting for publication. $\underline{17}$ 
Presentation type has been associated with the likelihood of publication. This study showed a higher publication rate for oral, compared to poster presentations; however, a weak correlation for publication between the presentation types was detected. Previous studies have suggested that more oral presentations became publications. $\underline{1}, \underline{9}, \underline{12}, \underline{13}, \underline{17}, \underline{18}, \underline{20}$ A meta-analysis by Scherer et al $\underline{20}$ showed that oral presentations were associated with full publications but not necessarily for randomized or controlled clinical trials, suggesting that the mode of presentation may not be a strong factor for publication. Other studies have also shown that there is no significant difference between oral presentations and poster presentations. $3,4,22$ In scientific meetings, oral presentations may have a more stringent selection process. The candidates are preselected by peers, based on the topic, quality of research, or significance of the results, and prioritized for entering research competitions. $\underline{17}, \underline{19}$ These abstracts may be more prepared for publication, compared to other presentations. Judging differences in quality of research between oral and poster presentation can be subjective; however, researchers should strive to publish their work, regardless of the type of presentation.

Outcomes, statistics, or funding may have an influence on a manuscript being published. In this study, strong associations were seen in neutral outcomes and funded studies with publication. Previous studies have shown that publication was associated with positive outcomes, $, \underline{2} \underline{10}, \underline{23}, \underline{24}$ having statistical significance, $, \underline{2} \underline{10}, \underline{23}, \underline{24}$ or being funded. $\underline{25}$ Some grants from government agencies, foundations, or universities require researchers to publish their work to fulfill the terms associated with the grant. Others have described publication bias associated with positive outcomes. $., \underline{5}, \underline{13}$ Disregarding negative outcomes can overlook important aspects associated with the research and inflate the positive outcomes. This potential publication bias has been criticized for jeopardizing the values behind evidence-based practice and may impact prosthodontics as well. This study did not examine any types of publication bias or relationship between positive outcomes and funding within prosthodontic research. Future studies in this area may be warranted.

Examining the topics in research can give an overview of the current trends in the field. As such, this study showed that the greatest amount of research was in fixed prosthodontics, assessment of color and esthetics, and implant prosthodontic research. Comparable numbers of abstracts for complete denture, overdenture, and other removable prosthodontics research were presented at the IADR meeting, yet publications in this area were lower than for fixed prosthodontics. Despite the direction of research trends, removable prosthodontic therapy remains a vital part of prosthodontics, and more publications from this area should be encouraged.

A global effort in the advancement of prosthodontics research was evident, where the top four countries for both abstracts and publications from each continent were: the US, Japan, Germany, and Brazil. Interestingly, by continent, Europe had the highest number of publications and had a strong association with abstracts and publications, while North America had the highest number of abstracts. The locations for the IADR events may influence abstract submission. The general sessions being held in the US, and Honolulu being close to Japan, may have had a regional influence on the number of abstracts presented by the US and Japan. It would be interesting to examine if abstracts from other years and their respective locations have any correlations with the number of abstracts and countries. Although similar, 
the top 10 affiliations for abstracts did not correlate with the top 10 affiliations for publications. Similarly, a study by Secil et al $\underline{14}$ showed that the origin of the abstracts was found not to be related to the likelihood of subsequent publication.

There are several limitations to this study. This study reported observations from the prosthodontics section of the IADR for 2004 and 2005. The results may not be applicable to other areas in dental research, and they may differ for other years. Only one database (PubMed) search in English was used for the data collection. This may have underestimated the number of published articles from the meeting. Also, certain manuscripts were excluded from analysis due to access or being published prior to the meeting. Many abstracts may have been in the process of getting published or accepted and waiting for publication. Including these manuscripts in the analysis could have changed the data. In this study, the quality of the abstract was not analyzed. Factors such as sample size, methodology (randomizing, blinding, etc), or multi-centered trials have been used to determine the hierarchy of evidence, $\underline{12}$ and this study did not relate such factors from the abstract to the reason for not being published. A deficiency in these factors can certainly influence the likelihood for publication. This area may be further explored in the future.

\section{Conclusions}

Within the limitations of this study, the following conclusions were drawn:

1 Although the publication rates were similar to other medical and dental literature, the majority of abstracts from the prosthodontics research section of IADR General Sessions in 2004 and 2005 remain unpublished after 5 years.

2 The characteristics and relationships between abstracts and published manuscripts were analyzed. A significant association for publication was noted for manuscripts with neutral outcomes, funding, and abstracts from Europe.

3 Despite challenges and delays that present prior to publication, more presenters should strive to disseminate the knowledge to the public.

\section{Acknowledgment}

The authors wish to thank Drs. Bradford Johnson, Edward Monaco, and Asbjorn Jokstad for their invaluable input in reviewing the manuscript.

\section{References}

${ }^{1}$ Hoag CC, Elterman DS, Macneily AE: Abstracts presented at the American Urological Association Annual Meeting: determinants of subsequent peer reviewed publication. $J$ Urol 2006;176:2624-2629; discussion 29.

2 Stern JM, Simes RJ: Publication bias: evidence of delayed publication in a cohort study of clinical research projects. Brit Med J 1997;315:640-645. 
${ }^{3} \mathrm{Ng} \mathrm{L}$, Hersey K, Fleshner N: Publication rate of abstracts presented at the annual meeting of the American Urological Association. BJU Int 2004;94:79-81.

${ }^{4}$ Autorino R, Quarto G, Di Lorenzo G, et al: Are abstracts presented at the EAU meeting followed by publication in peer-reviewed journals? A critical analysis. Eur Urol 2007;51:833-840; discussion 40.

${ }^{5}$ Autorino R, Quarto G, Di Lorenzo G, et al: What happens to the abstracts presented at the Societe Internationale d'Urologie meeting? Urology 2008;71:367-371.

${ }^{6}$ Bagheri SC, Lenox N, Verschueren DS, et al: Abstracts from the American Association Of Oral And Maxillofacial Surgeons annual scientific meeting: proportion published and time to publication. J Oral Maxillofac Surg 2005;63:838-840.

${ }^{7}$ Cartwright R, Khoo AK, Cardozo L: Publish or be damned? The fate of abstracts presented at the International Continence Society Meeting 2003. Neurourol Urodyn 2007;26:154157.

${ }^{8}$ DeMola PM, Hill DL, Rogers K, et al: Publication rate of abstracts presented at the shoulder and elbow session of the American Academy of Orthopaedic Surgery. Clin Orthop Relat Res 2009;467:1629-1633.

${ }^{9}$ Greenberg D, Wacht O, Pliskin JS: Peer review in publication: factors associated with the fulllength publication of studies presented in abstract form at the annual meeting of the Society for Medical Decision Making. Med Decis Making 2008;28:938-942.

${ }^{10}$ Harris IA, Mourad M, Kadir A, et al: Publication bias in abstracts presented to the annual meeting of the American Academy of Orthopaedic Surgeons. J Orthop Surg (Hong Kong) 2007;15:62-66.

11 Kleweno CP, Bryant WK, Jacir AM, et al: Discrepancies and rates of publication in orthopaedic sports medicine abstracts. Am J Sports Med 2008;36:1875-1879.

12 Peng PH, Wasserman JM, Rosenfeld RM: Factors influencing publication of abstracts presented at the AAO-HNS Annual Meeting. Otolaryngol Head Neck Surg 2006;135:197-203.

13 Sanossian N, Ohanian AG, Saver JL, et al: Frequency and determinants of nonpublication of research in the stroke literature. Stroke 2006;37:2588-2592.

${ }^{14}$ Secil M, Ucar G, Dicle O: Scientific papers presented at the 2000-2001 European Society of Gastrointestinal and Abdominal Radiology (ESGAR) meetings: publication rates during the period 2000-2004. Eur Radiol 2007;17:2183-2188.

15 Smollin CG, Nelson LS: Publication of abstracts presented at 2001 NAACT. J Med Toxicol 2006;2:97-100.

${ }^{16}$ Toma M, McAlister FA, Bialy L, et al: Transition from meeting abstract to full-length journal article for randomized controlled trials. J Am Med Assoc 2006;295:1281-1287.

17 Scholey JM, Harrison JE: Delay and failure to publish dental research. Evid Based Dent 2005;6:58-61.

${ }^{18}$ Dahllof G, Wondimu B, Maniere MC: Subsequent publication of abstracts presented at the International Association of Paediatric Dentistry meetings. Int J Paediatr Dent 2008;18:91-97. 
${ }^{19}$ Sprague S, Bhandari M, Devereaux PJ, et al: Barriers to full-text publication following presentation of abstracts at annual orthopaedic meetings. J Bone Joint Surg Am 2003;85-A:158-163.

20 Scherer RW, Langenberg P, von Elm E: Full publication of results initially presented in abstracts. Cochrane Database Syst Rev 2007;2:MR000005.

${ }^{21}$ Balasubramanian SP, Kumar ID, Wyld L, et al: Publication of surgical abstracts in full text: a retrospective cohort study. Ann R Coll Surg Engl 2006;88:57-61.

${ }^{22}$ Rao AR, Beatty JD, Laniado M, et al: Publication rate of abstracts presented at the British Association of Urological Surgeons Annual Meeting. BJU Int 2006;97:306-309.

${ }^{23}$ Dwan K, Altman DG, Arnaiz JA, et al: Systematic review of the empirical evidence of study publication bias and outcome reporting bias. PLoS One 2008;3:e3081.

${ }^{24}$ Hasenboehler EA, Choudhry IK, Newman JT, et al: Bias towards publishing positive results in orthopedic and general surgery: a patient safety issue? Patient Saf Surg 2007;1:1-4.

${ }^{25}$ Birkhahn RH, Van Deusen SK, Okpara OI, et al: Funding and publishing trends of original research by emergency medicine investigators over the past decade. Acad Emerg Med 2006;13:95-101.

${ }^{26}$ Lee MM, Gardiner J, Federico J, et al: A study of productivity and participation at IADR and AADR annual meetings from 1970 to 1981. J Dent Res 1983;62:578-580.

27 Jokstad A. Prosthodontics Group International Association for Dental Research. Available at http://www.iadr-prosthodontics.org/index.htm (Accessed March 16, 2010)

${ }^{28}$ Rahman M, Fukui T: Biomedical research productivity: factors across the countries. Int $\mathrm{J}$ Technol Assess Health Care 2003;19:249-252. 